Received: 24 November 2016

Accepted: 5 June 2017

Published online: 05 July 2017
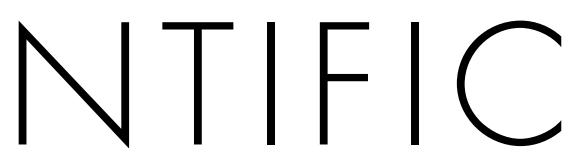

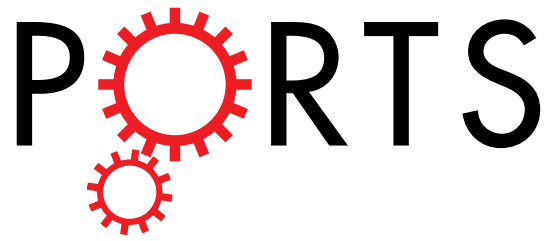

\title{
OPEN
}

\section{Temporal variation in associations between temperature and years of life lost in a southern China city with typical subtropical climate}

Guoxing $\mathrm{Li}^{1}$, Jing Huang ${ }^{1}$, Guozhang $\mathrm{Xu}^{2}$, Xiaochuan $\mathrm{Pan}^{1}$, Xujun Qian ${ }^{3}$, Jiaying $\mathrm{Xu}^{4}$, Yan Zhao ${ }^{1}$, Tao Zhang ${ }^{2}$, Qichen Liu ${ }^{1}$, Xinbiao Guo ${ }^{1}$ \& Tianfeng $\mathrm{He}^{2}$

Though some studies have explored the association between temperature and years of life lost (YLL), limited evidence is available regarding the effect of temporal variation on the temperature-YLL relationship, especially in developing countries. We explored temporal variation in the associations between temperature and YLL before and after 2013 heat waves (period I: Jan 2008 to Sep 2013, period II: Oct 2013 to Dec 2015) in Ningbo, a southern China city with typical subtropical climate. The heat associations showed an increasing trend. The number of $Y L L$ due to heat-related respiratory mortality was significantly higher in period II $(46.03,95 \% \mathrm{Cl}: 11.97,80.08)$ than in period I $(7.21,95 \% \mathrm{Cl}:-10.04$, 24.46) among married individuals. In contrast, the cold associations presented an attenuating trend, and the number of YLL due to non-accidental mortality was significantly lower in period II (262.32, $95 \% \mathrm{Cl}:-304.18,828.83)$ than in period I $(916.78,95 \% \mathrm{Cl}: 596.05,1237.51)$. These results indicate more effort still needed to be made to reduce heat-related YLL even after periods of extreme heat. Furthermore, using YLL provided complementary information for identifying vulnerable subgroups, which has important implications for the planning of public health interventions.

Cold and hot weather are established risk factors for human health, and abundant epidemiologic evidence has indicated their association with excess risk of mortality and morbidity, especially due to cardiovascular and respiratory diseases ${ }^{1-9}$. Interest in this field has increased after episodes of extreme weather and under climate change scenarios ${ }^{10}$.

Although consensus regarding the adverse influence of cold and hot temperatures has been reached, these associations remain to be explored in further detail. For instance, uncertainty regarding future temperature-health relationships is acknowledged as one of the most important barriers to projecting health impact in climate change studies $^{11,12}$.

Consequently, temporal variation in the association between temperature and health needs to be explored in depth to gain an understanding of the manner in which changes in exposure levels and implementation of public health interventions influence this relationship, thus providing evidence for the prediction of future temperature-related health burden under climate change scenarios. Previous studies have assessed temporal changes in temperature-related mortality in the USA ${ }^{13}$, Italy ${ }^{14,15}$, France ${ }^{16}$, Czech Republic ${ }^{17}$, etc.

In recent year, some studies have used years of life lost (YLL) as an index to estimate the relationship between temperature and disease burden ${ }^{18-22}$. YLL is a measure of disease burden that considers the life expectancy at death and, therefore, assigns higher weights to deaths that occur at younger ages ${ }^{23}$. This indicator has been extensively used to identify and prioritize causes of premature death around the world ${ }^{24}$. Evidence regarding the temperature-YLL relationship may provide additional information for policy making and health

${ }^{1}$ Department of Occupational and Environmental Health Sciences, Peking University School of Public Health, 38 Xueyuan Road, 100191, Beijing, China. ${ }^{2}$ Ningbo Municipal Center for Disease Control and Prevention, 237 Yongfeng Road, 315010, Ningbo, China. ${ }^{3}$ Ningbo First Hospital, Liuting Street, 315010, Ningbo, China. ${ }^{4}$ Tulan University, 6823 St. Charles Avenue, New Orleans, LA, 70118, USA. Guoxing Li and Jing Huang contributed equally to this work. Correspondence and requests for materials should be addressed to X.G. (email: guoxb@bjmu.edu.cn) orT.H. (email: hetf@nbcdc.org.cn) 


\begin{tabular}{|c|c|c|c|c|c|c|c|c|}
\hline Variables & $\min$ & q25 & median & q75 & $\max$ & IQR & mean & SD \\
\hline \multicolumn{9}{|c|}{ Daily meteorological measures } \\
\hline Temperature $\left({ }^{\circ} \mathrm{C}\right)$ & -2.2 & 9.9 & 18.9 & 25.0 & 34.4 & 15.1 & 17.6 & 8.8 \\
\hline Relative humidity (\%) & 19.0 & 66.0 & 74.0 & 82.0 & 97.0 & 16.0 & 73.2 & 12.0 \\
\hline \multicolumn{9}{|c|}{ Daily years of life lost (year) } \\
\hline Non-accidental & 753.6 & 1569.9 & 1771.4 & 2004.1 & 3362.1 & 434.2 & 1798.3 & 323.3 \\
\hline Cardiovascular & 128.5 & 361.8 & 447.0 & 540.3 & 1107.4 & 178.4 & 459.0 & 134.5 \\
\hline Respiratory & 30.4 & 140.5 & 192.5 & 254.1 & 654.7 & 113.6 & 203.7 & 86.3 \\
\hline ge $<75$ & 371.1 & 980.1 & 1131.8 & 1280.1 & 2348.6 & 300.0 & 1139.5 & 226.4 \\
\hline Age $\geq 75$ & 271 & 535.6 & 631.9 & \begin{tabular}{|l|}
763.8 \\
\end{tabular} & \begin{tabular}{|l|}
1297.4 \\
\end{tabular} & 228.2 & 658.8 & 169.7 \\
\hline Male & 429.1 & 946 & 1085.8 & 1243.1 & 2193.2 & 297.1 & 1100.8 & 223.8 \\
\hline Female & 236.6 & 574.7 & 683.4 & 806.9 & 1369 & 232.2 & 697.5 & 171.9 \\
\hline Married & 535.0 & 1093.3 & 1246.9 & 1407.7 & 2387.6 & 314.4 & 1256.2 & 231.8 \\
\hline Widowed & 134.4 & 317.5 & 388.7 & 477.6 & 1028.8 & 160.1 & 404.8 & 119.5 \\
\hline \multicolumn{9}{|c|}{ Daily deaths counts (No. of death) } \\
\hline Non-accidental & 45 & 77 & 88 & 102 & 166 & 25 & 90.3 & 18.3 \\
\hline Cardiovascular & 8 & 22 & 27 & 33 & 60 & 11 & 27.7 & 8.3 \\
\hline Respiratory & 2 & 11 & 14 & 19 & 45 & 8 & 15.4 & 6.2 \\
\hline Age $<75$ & 15 & 31 & 35 & 40 & 75 & 9 & 35.5 & 6.8 \\
\hline Age $\geq 75$ & 22 & 44 & 52 & 64 & 108 & 20 & 54.8 & 14.7 \\
\hline Male & 24 & 43 & 50 & 58 & 102 & 15 & 51.0 & 10.7 \\
\hline Female & 15 & 32 & 38 & 46 & 79 & 14 & 39.3 & 10.0 \\
\hline Married & 24 & 46 & 53 & 61 & 105 & 15 & 53.5 & 10.5 \\
\hline Widowed & 11 & 26 & 31 & 39 & 76 & 13 & 32.8 & 9.8 \\
\hline
\end{tabular}

Table 1. Descriptive statistics of meteorological factors, years of life lost and mortality from 2008 to 2015 in Ningbo, China.

resource allocation. However, insights into the temporal variations in the temperature-YLL associations due to cause-specific mortality are limited, and the modifications of socioeconomic factors such, as marital status, are unclear.

Ningbo, located in the Yangtze River Delta in southern China, is the world's fourth-largest port city. The population in Ningbo was estimated to be 7.83 million in 2015. Ningbo has a typical subtropical climate, with a hot summer and a mild winter. In 2013, the frequency of extremely hot days in the summer clearly exceeded that of other years in this southern Chinese city. The evaluation of temporal variation in the association between temperature and health before and after this period may have great importance for policy making regarding and the prediction of climate change in subtropical climate regions.

In order to provide evidence for the prediction of temperature-health associations and planning of public health interventions in subtropical climate regions under climate-change scenarios, we investigated temporal variation in associations between temperature and YLL due to cause-specific mortality in Ningbo, a southern Chinese city with typical subtropical climate during 2008-2015. In addition, the modifications of socioeconomic factors were also explored.

\section{Results}

Descriptive statistics. Table 1 shows the descriptive data for meteorological conditions, daily numbers of non-accidental, cardiovascular and respiratory deaths and their corresponding YLL in Ningbo during 2008 to 2015. The mean temperature was $17.6^{\circ} \mathrm{C}$, with a range from $-2.2^{\circ} \mathrm{C}$ to $34.4^{\circ} \mathrm{C}$ identified during these years. Mean daily numbers of non-accidental, cardiovascular and respiratory deaths were $90.3,27.7$, and 15.4, respectively. The corresponding mean YLL were 1798.3, 459.0 and 203.7 for the three categories of diseases. The average daily YLL were higher in younger, male and married people than in elderly, female and widowed individuals, respectively.

Overall cumulative associations. Figure 1 shows the exposure-response curves for the effects of daily mean temperature on YLL. In this figure, we detected the minimum mortality temperature (MMT), which indicated the temperature at which the lowest mortality risk occurs over the whole study period. When the temperature was higher or lower than MMP, mortality risk was expected to increase along with an increase or decrease of the temperature. Exploring MMT is important for policy making and health protection. All curves were $\mathrm{U}$-shaped, with an MMT between $25^{\circ} \mathrm{C}$ and $30^{\circ} \mathrm{C}$ identified for non-accidental, cardiovascular and respiratory deaths. The lag effects of temperature on YLL showed that the cold effects peaked at 2 days post-exposure and declined slowly over the following 20 days, while the hot associations appeared acutely and declined rapidly over the following 2-3 days (Fig. 2). Therefore, we presented the cumulative hot and cold associations using a lag period of 21 days, which was sufficient to capture the lag associations of temperature. 

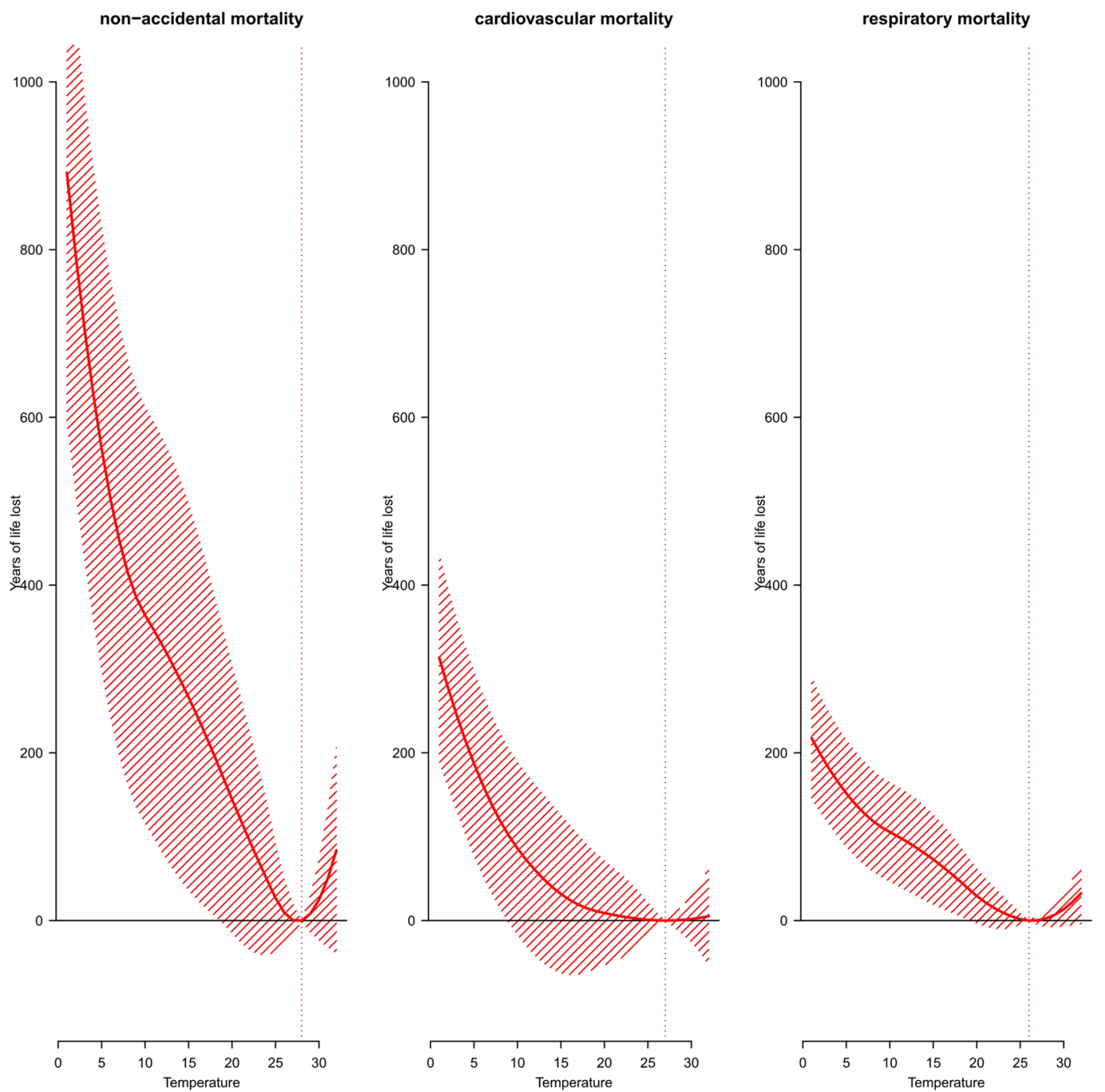

Figure 1. Overall cumulative exposure-response curves for the associations between temperature and years of life lost due to cause-specific mortality (non-accidental mortality, cardiovascular mortality, respiratory mortality) with $95 \%$ confidence intervals. The vertical lines represent the percentile of the minimum mortality temperature (dotted).

The cumulative temperature-YLL associations due to non-accidental, cardiovascular, and respiratory mortality are shown in Table 2 . In general, increased YLL were associated with high and low temperature exposure, and the cold associations were stronger than the hot associations.

Temporal variation. The major results of the analysis of temporal variation in the association between temperature and YLL are summarized in Table 2 and Figs 3-5 (Fig. 3 for non-accidental disease, Fig. 4 for cardiovascular disease, Fig. 5 for respiratory disease). The figures show the exposure-response curves predicted based on the time-varying distributed lag non-linear model (DLNM) for period I (Jan 2008 to Sep 2013, Red Line) and period II (Oct 2013 to Dec 2015, Blue Line).

In general, the analysis suggested that the trend in heat-related YLL was steeper in period II than period I. When stratified by modifying factors, the YLL due to heat-related respiratory mortality were significantly higher in period II $(46.03,95 \%$ CI: $11.97,80.08)$ years than in period I $(7.21,95 \%$ CI: $-10.04,24.46)$ years in married individuals. In contrast, the cold associations presented an attenuating trend, and the YLL due to non-accidental mortality was significantly lower in period II $(262.32,95 \%$ CI: $-304.18,828.83)$ years than in period I (916.78, $95 \%$ CI: $596.05,1237.51$ ) years. In the stratification analysis, YLL also showed a significant decrease, and the YLL due to non-accidental and respiratory mortality was significantly lower in the elderly and widowed individuals in period II than period I. In addition, the analysis of the curves suggested that more pronounced variations were associated with extreme temperatures (Figs 3-5).

The estimates for the temporal variation in the temperature-mortality association are presented in Table 3. Similar trends were identified; in particular, respiratory mortality exhibited the greatest relative increase in association with the effect of heat, and non-accidental mortality presented the greatest relative decrease in cold 
(A) var=3

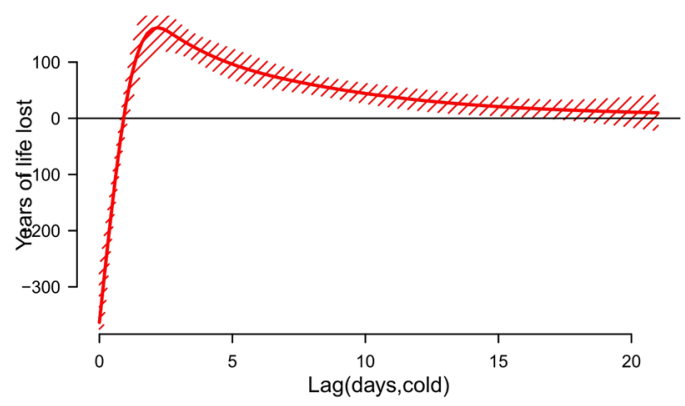

(B) $\operatorname{var}=3$

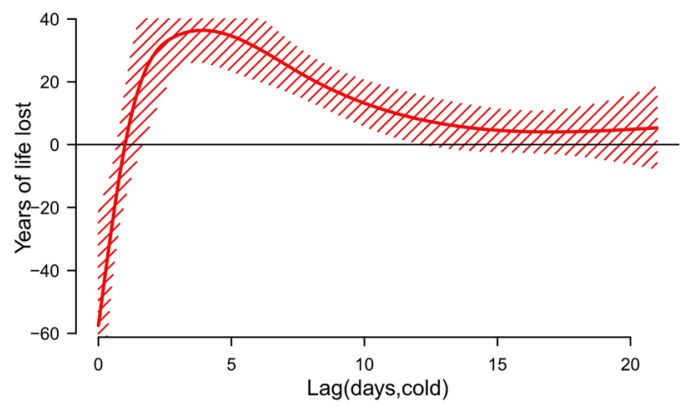

(C) var=3

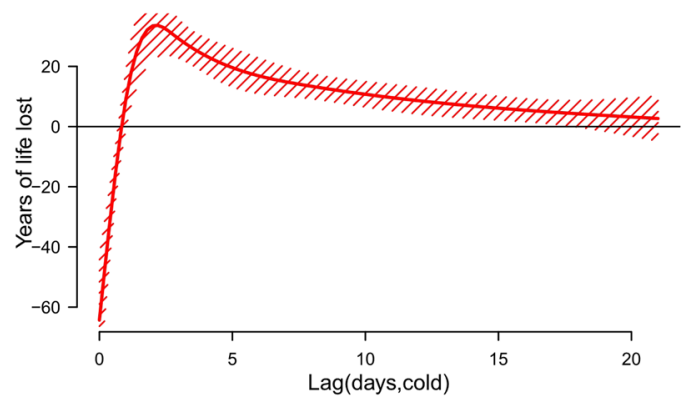

(A) $\operatorname{var}=30$

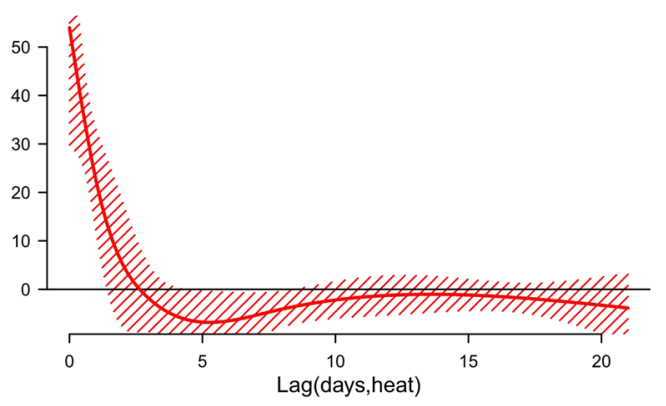

(B) $\operatorname{var}=30$

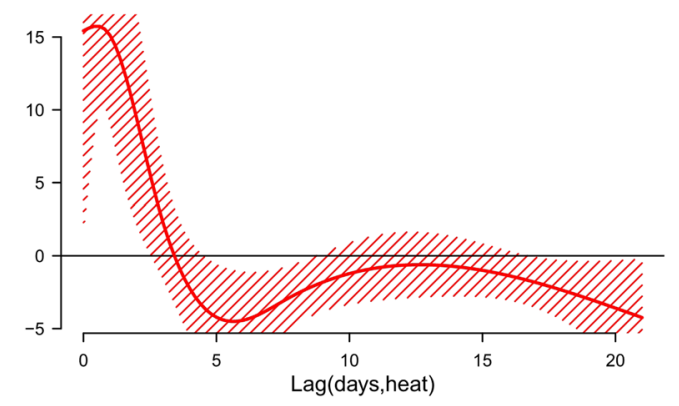

(C) var=30

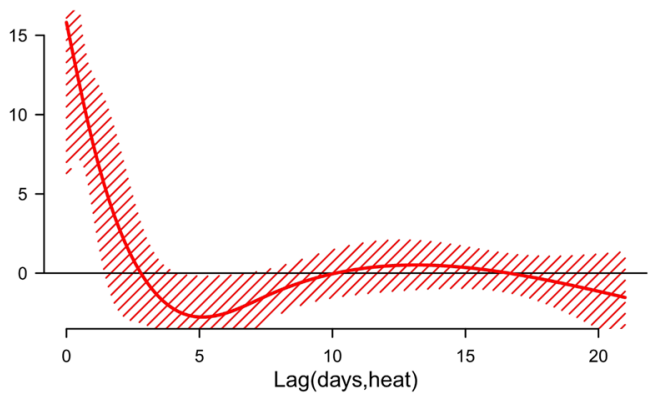

Figure 2. Lag-response curve for the association between heat and years of life lost due to cause-specific mortality ((A) non-accidental mortality, (B) cardiovascular mortality, (C) respiratory mortality), with 95\% confidence intervals. These curves were computed based on temperatures corresponding to the $95^{\text {th }} \& 5^{\text {th }}$ percentiles and compared with the minimum mortality temperature.

associations, with relative risk (RR) at the $95^{\text {th }}$ temperature percentile increasing from 1.08 (95\% CI: $\left.0.97,1.20\right)$ in period I to $1.44(95 \% \mathrm{CI}: 1.16,1.80)$ in period II, and RR at the $5^{\text {th }}$ temperature percentile dropping from 1.90 (95\% CI:1.62, 2.22) in period I to 1.34 (95\% CI: $1.02,1.77)$ in period II.

Subgroup comparisons. In general, the elderly tended to have higher YLL associated with both hot and cold temperatures than did younger individuals. However, significant differences were only observed in cold-related respiratory disease during period I, with an increase of 204.72 (95\% CI: 148.44, 261.00) years in YLL observed in the elderly and a change of 27.61 (95\% CI: -23.48, 78.69) years in YLL observed in younger individuals. When gender was considered as a modifying factor, a higher number of YLL of cold-related respiratory deaths were observed in males relative to females during period I. For marital status, the results showed that YLL were higher among married than widowed individuals, while a significant difference was only detected in heat-related respiratory disease during period II, with an increase of 46.03 (95\% CI: 11.97, 80.08) years in YLL observed in married individuals and a change of 21.21 (95\% CI: -3.67, 46.10) years in YLL observed in widowed individuals. When stratified marital status by age, YLL were also higher among married than widowed people. For instance, an increase of 32.88 (95\% CI: 8.59, 57.17) years and a change of 3.39 (95\% CI: -7.34, 14.21) years in YLL observed in married and widowed people who were less than 75 years old, respectively. The detailed results were presented in Table S5.

When stratified by age and gender, the temperature-mortality association and the temperature-YLL relationship showed the same trend. However, when modified by marital status, they were different (Table 3). Widowed individuals tended to be at higher risk than married individuals. A significant difference was detected in cold-related respiratory disease during period I, with increased risks of 2.36 (95\% CI: 1.85, 3.02) and 1.67 (95\% 


\begin{tabular}{|c|c|c|c|c|c|}
\hline \multirow[b]{2}{*}{$\begin{array}{l}\text { Health } \\
\text { Endpoints }\end{array}$} & \multirow[b]{2}{*}{ Group } & \multicolumn{2}{|l|}{ Period } & \multicolumn{2}{|l|}{ Period } \\
\hline & & $\begin{array}{l}\text { Jan 2008-Sep } 2013 \\
\text { Cold: } 5 \text { th vs MMP }\end{array}$ & $\begin{array}{l}\text { Oct 2013-Dec } 2015 \\
\text { Cold: 5th vs MMP }\end{array}$ & $\begin{array}{l}\text { Jan 2008-Sep } 2013 \\
\text { Hot: 95th vs MMP }\end{array}$ & $\begin{array}{l}\text { Oct 2013-Dec } 2015 \\
\text { Hot: 95th vs MMP }\end{array}$ \\
\hline \multirow{7}{*}{ Non-accidental } & ALL & $916.78(596.05,1237.51)$ & $262.32(-304.18,828.83) *$ & $26.73(-25.92,79.37)$ & $85.52(-48.98,220.03)$ \\
\hline & $\begin{array}{l}\text { Younger } \\
(<75)\end{array}$ & $332.24(57.52,606.96)$ & $19.41(-465.83,504.65)$ & $12.74(-32.35,57.83)$ & $26.16(-89.05,141.37)$ \\
\hline & Older $(\geq 75)$ & $584.53(447.40,721.66)$ & $242.91(0.70,485.13)^{*}$ & $13.98(-8.52,36.49)$ & $59.36(1.85,116.87)$ \\
\hline & Male & $476.05(227.70,724.41)$ & $355.39(-83.27,794.06)$ & $12.83(-27.93,53.60)$ & $70.70(-33.45,174.85)$ \\
\hline & Female & $440.72(252.29,629.15)$ & $-93.07(-425.89,239.76)^{*}$ & $13.89(-17.04,44.82)$ & $14.82(-64.20,93.85)$ \\
\hline & Married & $504.75(241.06,768.43)$ & $302.32(-163.44,768.08)$ & $21.37(-21.91,64.65)$ & $61.94(-48.65,172.52)$ \\
\hline & Widowed & $365.64(255.846,475.44)$ & $-29.21(-223.14,164.73) *$ & $13.73(-4.30,31.75)$ & $21.64(-24.41,67.68)$ \\
\hline \multirow{7}{*}{ Cardiovascular } & ALL & $290.60(156.40,424.80)$ & $174.88(-65.38,415.14)$ & $2.40(-28.49,33.29)$ & $15.71(-55.23,86.64)$ \\
\hline & $\begin{array}{l}\text { Younger } \\
(<75)\end{array}$ & $94.02(-13.06,201.12)$ & $77.43(-114.29,269.14)$ & $-5.80(-30.45,18.85)$ & $9.07(-47.53,65.67)$ \\
\hline & Older $(\geq 75)$ & $196.58(119.01,274.15)$ & $97.45(-41.42,236.33)$ & $8.20(-9.65,26.05)$ & $6.63(-34.37,47.63)$ \\
\hline & Male & $101.11(0.27,201.94)$ & $54.76(-125.76,235.28)$ & $-10.43(-33.64,12.78)$ & $-7.90(-61.20,45.40)$ \\
\hline & Female & $189.49(107.13,271.86)$ & $120.12(-27.34,267.57)$ & $12.83(-6.13,31.78)$ & $23.61(-19.93,67.14)$ \\
\hline & Married & $174.11(63.64,284.57)$ & $106.69(-91.06,304.46)$ & $-1.26(-26.69,24.16)$ & $7.86(-50.53,66.24)$ \\
\hline & Widowed & $115.62(53.76,177.48)$ & $23.80(-86.95,134.55)$ & $3.21(-11.03,17.45)$ & $-0.82(-33.52,31.88)$ \\
\hline \multirow{7}{*}{ Respiratory } & ALL & $232.33(154.21,310.44)$ & $80.74(-59.87,221.36)$ & $10.83(-12.52,34.19)$ & $59.76(13.65,105.88)$ \\
\hline & \begin{tabular}{|l|}
$\begin{array}{l}\text { Younger } \\
(<75)\end{array}$ \\
\end{tabular} & $27.61(-23.48,78.69)$ & $22.69(-69.26,114.64)$ & $-2.05(-17.32,13.22)$ & $24.30(-5.86,54.45)$ \\
\hline & Older $(\geq 75)$ & $204.72(148.44,261.00)$ & $58.05(-43.25,159.36)^{*}$ & $12.88(-3.94,29.71)$ & $35.47(2.24,68.69)$ \\
\hline & Male & $164.39(106.38,222.40)$ & $38.86(-65.57,143.28)^{*}$ & $12.04(-5.31,29.38)$ & $30.39(-3.86,64.63)$ \\
\hline & Female & $67.93(18.88,116.99)$ & $41.89(-46.41,130.19)$ & $-1.20(-15.87,13.46)$ & $29.38(0.42,58.34)$ \\
\hline & Married & $102.28(44.59,159.97)$ & $61.65(-42.20,165.49)$ & $7.21(-10.04,24.46)$ & $46.03(11.97,80.08)^{*}$ \\
\hline & Widowed & $132.90(90.74,175.05)$ & $18.30(-57.59,94.18)^{*}$ & $9.10(-3.50,21.71)$ & $21.21(-3.67,46.10)$ \\
\hline
\end{tabular}

Table 2. The cumulative cold and hot effects on years of life lost due to non-accidental, cardiovascular, and respiratory mortality. MMP: minimum mortality percentile; The MMP for YLL of non-accidental, cardiovascular and respiratory mortality were 87,83 and 79 percentiles, respectively. The 5 th and 95 th percentiles temperatures were $3.0^{\circ} \mathrm{C}$ and $30.4^{\circ} \mathrm{C}$. $* P<0.05$ (comparison between two periods).

CI: $1.38,2.03)$ observed in widowed and married individuals, respectively. When considering age in different marital status, similar results were shown. For example, increased risks of 2.52 (95\% CI: 1.95, 3.26) and 2.11 $(95 \%$ CI: $1.59,2.79)$ detected in married and widowed people older than 75 years, respectively. More details were presented in Table S6.

Sensitivity analyses results. Sensitivity analyses were performed to test whether the results were robust based on the variation of the parameters in the model. The supplemental material shows that the estimations were stable when extending the maximum lag period to 27 days (see Supplementary Fig. S1), using 6 or 8 degrees of freedom per year for the time variable (see Supplementary Figs S2 and S3), removing relative humidity from the analysis (see Supplementary Fig. S4).

\section{Discussion}

The study found hot and cold temperatures had significant influences on YLL due to non-accidental, cardiovascular and respiratory mortality in general. In addition, the results indicated that an increase in YLL was associated with heat, while an attenuating trend was observed in association with cold after an extreme hot period in a southern Chinese city with typical subtropical climate.

The hot associations were acute and lasted for 2-3 days, while the cold associations were delayed and lasted for approximately 20 days. This evidence may provide information for public health and other relevant departments to develop early response plans for cold and hot temperatures. Furthermore, the results of our study showed that the associations of cold were stronger than the associations of heat, which was consistent with previous studies ${ }^{19,25}$. Ningbo is a southern Chinese city with a typical subtropical climate, and the annual mean temperature is relatively high. The residents in this subtropical region may have stronger physiological and behavioural adaptions to high temperatures, while their adaptive capacity to cold is relatively weak. A previous study also showed that the effect of cold in warmer cities was increased relative to that in cold cities ${ }^{26}$. This information also indicated that the adverse influence of low temperature should not be ignored in subtropical regions, even under the global warming scenario.

The study identified an increasing YLL trend after the extremely hot period, although the mean $\left(26.5^{\circ} \mathrm{C}\right)$ and maximum summer temperatures $\left(31.9^{\circ} \mathrm{C}\right)$ were lower in period II when compared with the mean $\left(28.0^{\circ} \mathrm{C}\right)$ and maximum summer temperatures $\left(33.3^{\circ} \mathrm{C}\right.$ ) in period I (Supplementary Table S1). In addition, this result was discordant with the findings of previous studies, which indicated that heat-related associations decreased after the specific weather events ${ }^{15-17}$. 


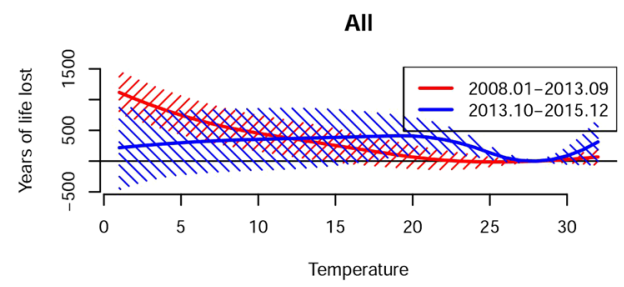

Younger $(<75)$

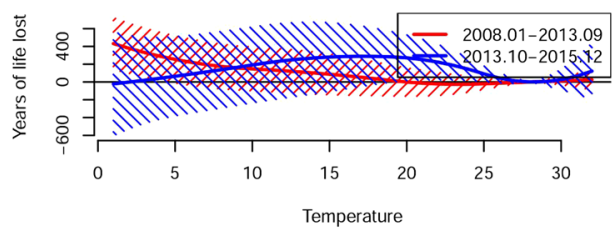

Male

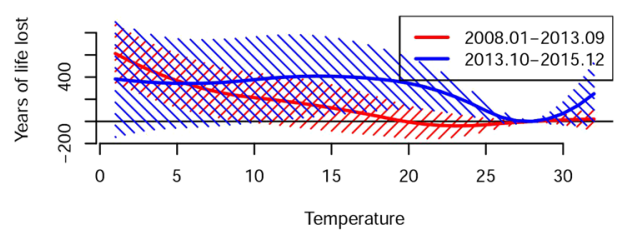

Married

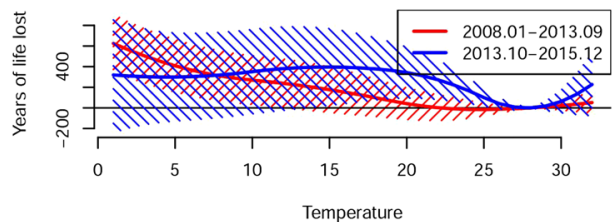

Married(>=75)

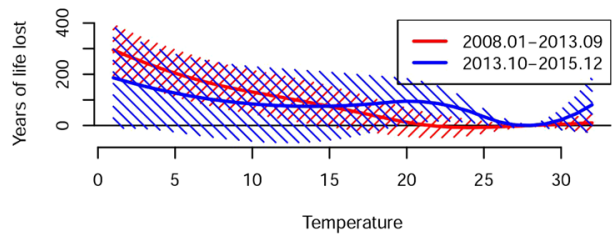

Married(<75)

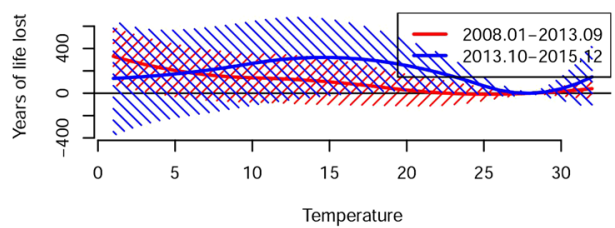

Elderly(>=75)

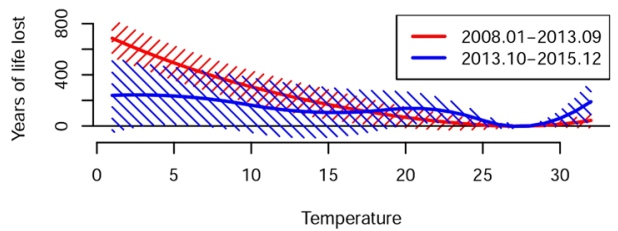

Female

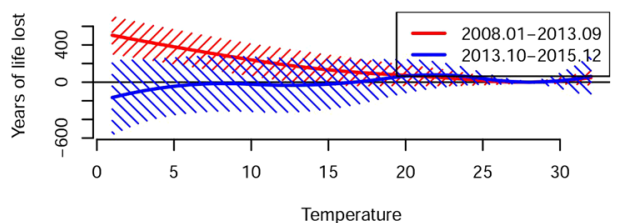

Widowed

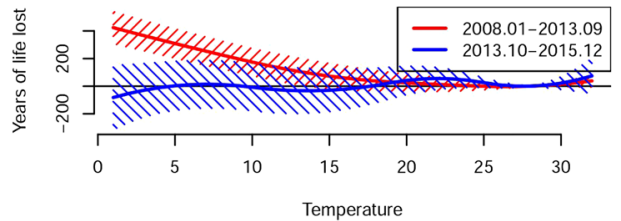

Widowed(>=75)

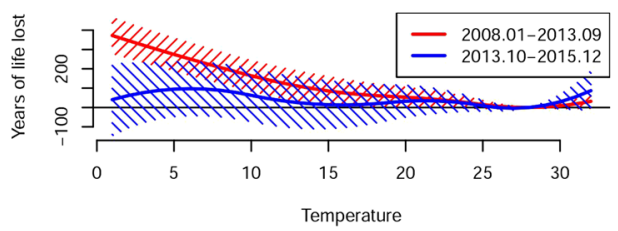

Widowed(<75)

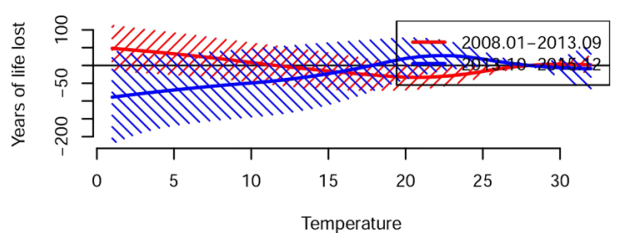

Figure 3. Overall cumulative exposure-response curves (with $95 \%$ confidence intervals) for the association between temperature and years of life lost due to non-accidental mortality during period I (Jan 2008 to Sep 2013, red) and period II (Oct 2013 to Dec 2015, blue).

Changes in temperature-related associations over a long period of time may be explained by infrastructural changes, such as improvements in housing and health service and physiological acclimatization ${ }^{27,28}$. However, over a relatively short period of time, any changes in infrastructure and physiological acclimatization would likely be small. Studies comparing the association between heat and mortality before and after the 2003 heat waves in Europe indicated that the implementation of public health interventions may have played an important role in reducing the risk ${ }^{15-17}$.

To our knowledge, many interventions were implemented during the extremely hot period in Ningbo in 2013. These interventions included the issuance of early warning information by the meteorological and health 


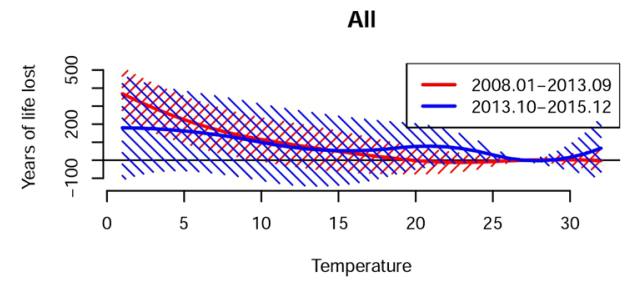

Younger $(<75)$

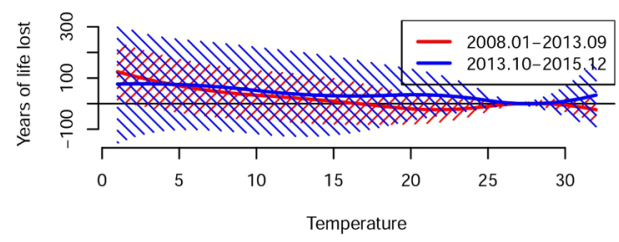

Male

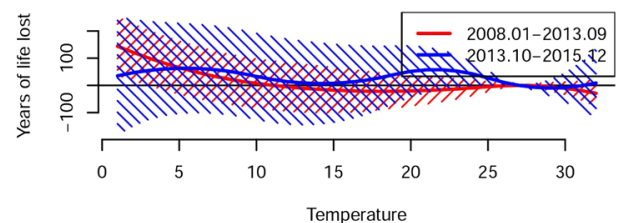

Married

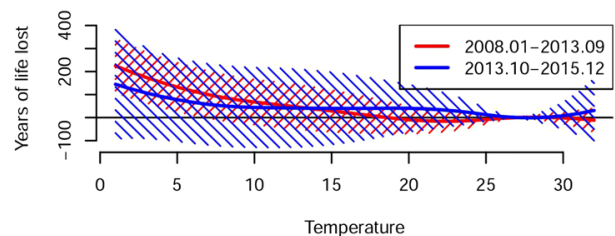

Married(>=75)

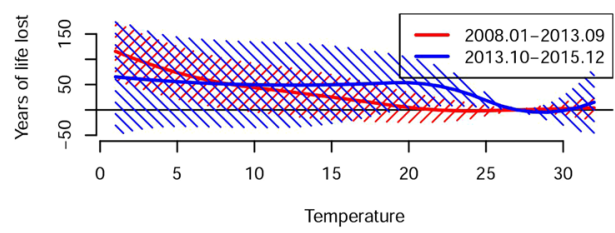

Married(<75)

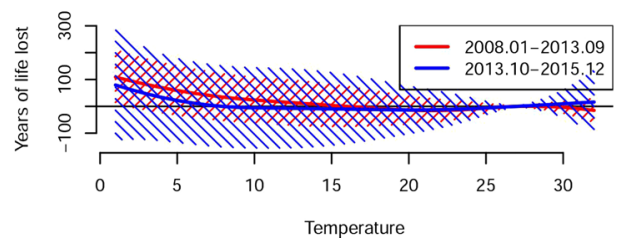

Elderly $(>=75)$

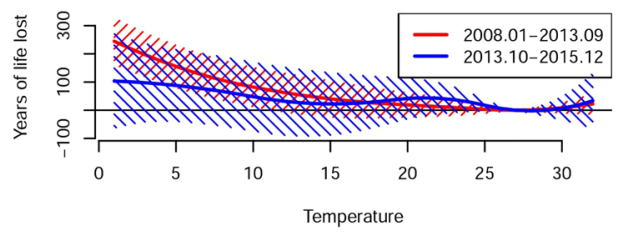

Female

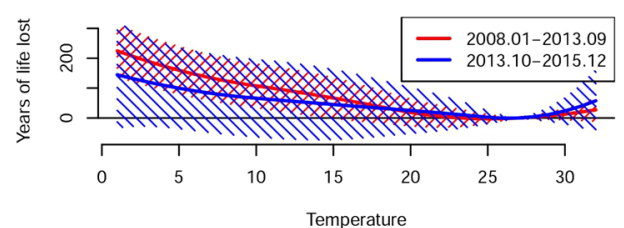

Widowed

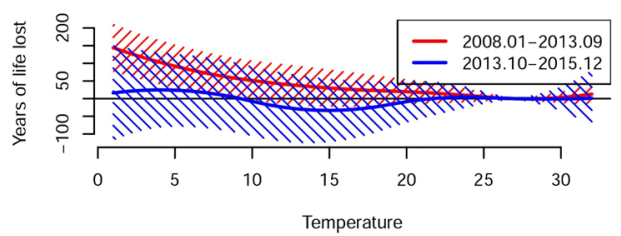

Widowed(>=75)

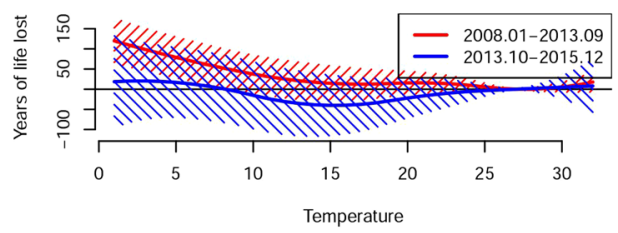

Widowed(<75)

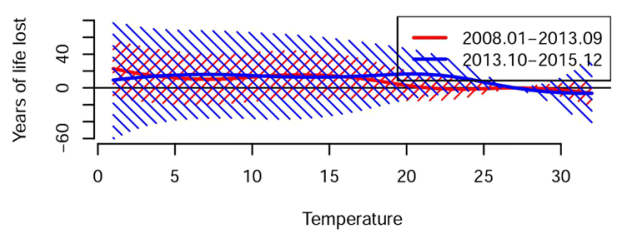

Figure 4. Overall cumulative exposure-response curves (with $95 \%$ confidence intervals) for the association between temperature and years of life lost due to cardiovascular mortality during period I (Jan 2008 to Sep 2013) (red) and period II (Oct 2013 to Dec 2015) (blue).

departments, increased heat stroke surveillance, and restriction of outdoor work during the extreme hot period. The results indicated these interventions were effective at reducing health risks during this extreme hot period. This may be because, beyond the effects of the intervention programmes itself, such interventions may increase the level of awareness regarding the health risks associated with extreme temperatures, promote behavioural adaptation, etc. However, after the extremely hot period, the mean and maximum temperatures decreased, and it was possible that decreased attention was paid to temperature-related health risks, reducing the effectiveness of the interventions; therefore, the health risks associated with hot temperature increased during this period. 


\section{All}

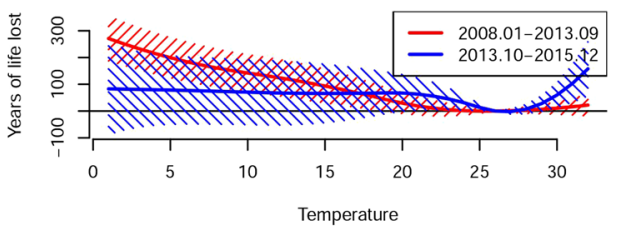

Younger $(<75)$

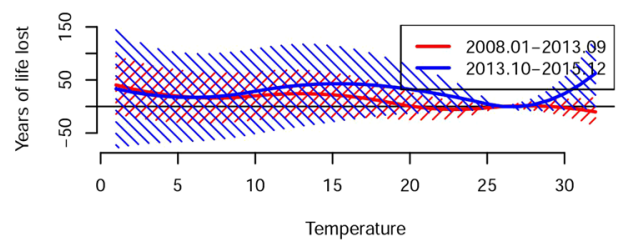

Male

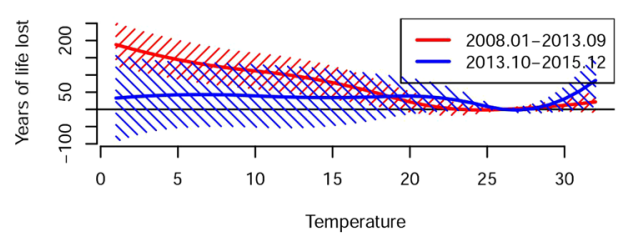

Married

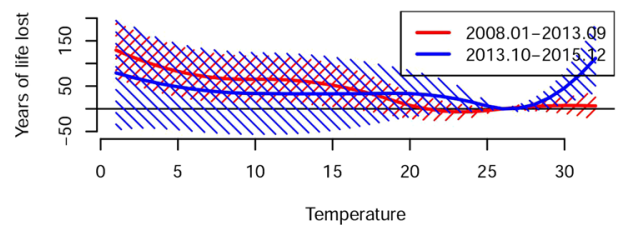

Married(>=75)

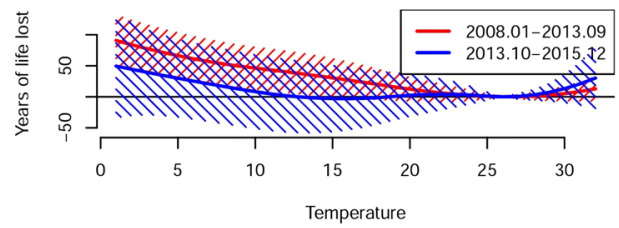

Married(<75)

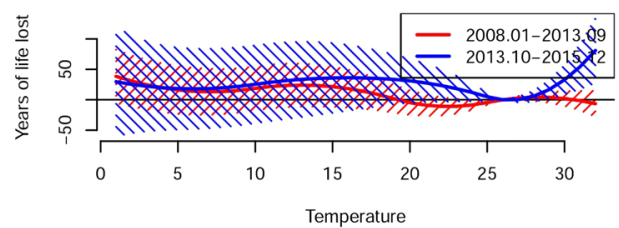

Elderly $(>=75)$

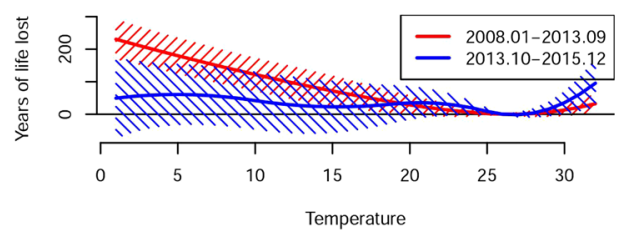

Female

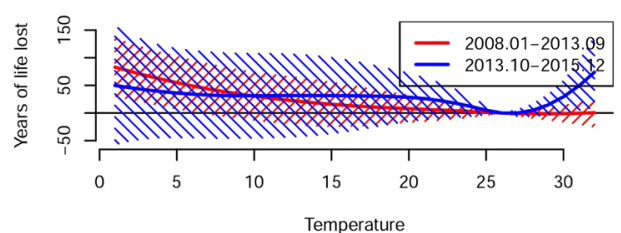

Widowed

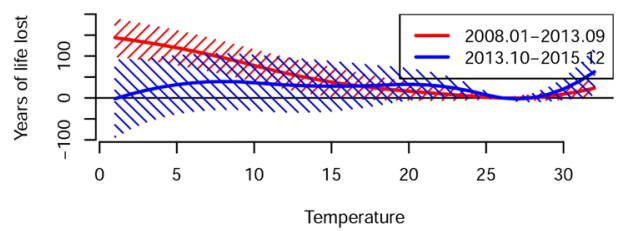

Widowed(>=75)

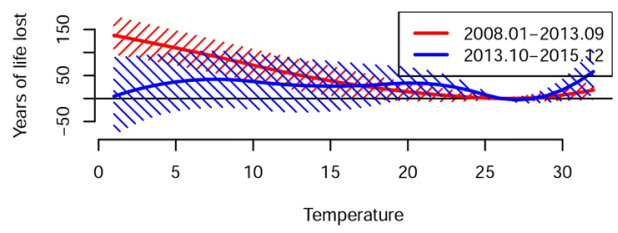

Widowed(<75)

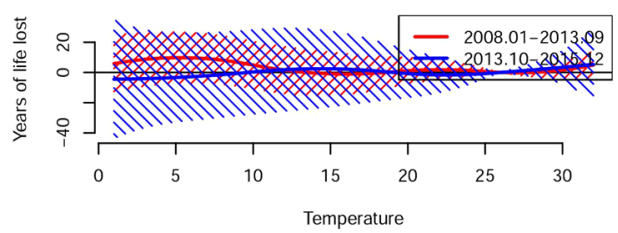

Figure 5. Overall cumulative exposure-response curves (with 95\% confidence intervals) for the association between temperature and years of life lost due to respiratory mortality during period I (Jan 2008 to Sep 2013) (red) and period II (Oct 2013 to Dec 2015) (blue).

Contrary to the increased YLL observed in association with the heat associations, temporal variations in the cold associations exhibited an attenuating trend. The mean and minimum winter temperatures were $11.2^{\circ} \mathrm{C}$ and $0.6^{\circ} \mathrm{C}$, respectively, in period II, which were higher than the mean $\left(10.5^{\circ} \mathrm{C}\right)$ and minimum winter temperatures $\left(-1.1^{\circ} \mathrm{C}\right.$ ) in period I (see Supplementary Table S1). The lower impact of cold observed during the latter period relative to the former period may be partly explained by the mild winter temperatures observed during the latter period. The results regarding the aforementioned temporal variations may have important implications for the prediction of and policy making related to climate change in subtropical climate regions. 


\begin{tabular}{|c|c|c|c|c|c|}
\hline \multirow[b]{2}{*}{ Health Endpoints } & \multirow[b]{2}{*}{ Group } & \multicolumn{2}{|l|}{ Period } & \multicolumn{2}{|l|}{ Period } \\
\hline & & \begin{tabular}{|l|} 
Jan 2008-Sep 2013 \\
Cold: 5th vs MMP
\end{tabular} & $\begin{array}{l}\text { Oct 2013-Dec } 2015 \\
\text { Cold: 5th vs MMP }\end{array}$ & $\begin{array}{l}\text { Jan 2008-Sep } 2013 \\
\text { Hot: 95th vs MMP }\end{array}$ & $\begin{array}{l}\text { Oct 2013-Dec 2015 } \\
\text { Hot: 95th vs MMP }\end{array}$ \\
\hline \multirow{7}{*}{ Non-accidental mortality } & ALL & $1.90(1.62,2.22)$ & $1.34(1.02,1.77)^{*}$ & $1.03(0.99,1.07)$ & $1.08(0.99,1.17)$ \\
\hline & Younger $(<75)$ & $1.39(1.11,1.73)$ & $1.08(0.72,1.61)$ & $1.03(0.98,1.09)$ & $1.02(0.90,1.15)$ \\
\hline & Older $(\geq 75)$ & $2.34(1.92,2.85)$ & $1.51(1.07,2.13)^{*}$ & $1.02(0.97,1.07)$ & $1.12(1.01,1.25)$ \\
\hline & Male & $1.78(1.46,2.17)$ & $1.48(1.05,2.10)$ & $1.03(0.98,1.08)$ & $1.05(0.95,1.17)$ \\
\hline & \begin{tabular}{|l|} 
Female \\
\end{tabular} & $2.06(1.65,2.58)$ & $1.17(0.79,1.74)^{*}$ & $1.03(0.98,1.09)$ & $1.11(0.98,1.26)$ \\
\hline & Married & $1.67(1.38,2.03)$ & $1.42(1.02,1.98)$ & $1.03(0.99,1.08)$ & $1.05(0.95,1.16)$ \\
\hline & Widowed & $2.36(1.85,3.02)$ & $1.22(0.79,1.89)^{*}$ & $1.03(0.97,1.09)$ & $1.10(0.96,1.27)$ \\
\hline \multirow{7}{*}{ Cardiovascular mortality } & ALL & $1.86(1.43,2.42)$ & $1.45(0.93,2.27)$ & $1.03(0.97,1.10)$ & $1.04(0.90,1.19)$ \\
\hline & Younger $(<75)$ & $1.59(0.99,2.55)$ & $1.44(0.60,3.46)$ & $0.98(0.88,1.10)$ & $1.01(0.77,1.32)$ \\
\hline & Older $(\geq 75)$ & $1.98(1.45,2.70)$ & $1.46(0.87,2.42)$ & $1.05(0.97,1.13)$ & $1.04(0.89,1.22)$ \\
\hline & Male & $1.52(1.07,2.16)$ & $1.41(0.77,2.57)$ & $0.99(0.90,1.08)$ & $0.96(0.80,1.16)$ \\
\hline & Female & $2.29(1.59,3.31)$ & $1.47(0.79,2.72)$ & $1.08(0.98,1.18)$ & $1.12(0.92,1.36)$ \\
\hline & Married & $1.81(1.27,2.57)$ & $1.49(0.82,2.71)$ & $1.02(0.93,1.11)$ & $1.02(0.85,1.23)$ \\
\hline & Widowed & $1.98(1.33,2.93)$ & $1.27(0.65,2.47)$ & $1.04(0.94,1.14)$ & $1.02(0.83,1.26)$ \\
\hline \multirow{7}{*}{ Respiratory mortality } & ALL & $2.82(2.03,3.93)$ & $1.76(0.95,3.26)$ & $1.08(0.97,1.20)$ & $1.44(1.16,1.80)^{*}$ \\
\hline & Younger $(<75)$ & $1.53(0.63,3.74)$ & $2.07(0.36,12.00)$ & $1.01(0.75,1.35)$ & $1.90(1.02,3.54)$ \\
\hline & Older $(\geq 75)$ & $3.09(2.18,4.39)$ & $1.74(0.91,3.327)$ & $1.09(0.97,1.22)$ & $1.39(1.10,1.76)$ \\
\hline & Male & $3.94(2.51,6.19)$ & $1.58(0.69,3.62)$ & $1.09(0.94,1.26)$ & $1.32(0.98,1.77)$ \\
\hline & Female & $2.00(1.26,3.16)$ & $1.96(0.82,4.69)$ & $1.07(0.91,1.25)$ & $1.61(1.17,2.21)^{*}$ \\
\hline & Married & $2.48(1.51,4.07)$ & $2.05(0.83,5.03)$ & $1.03(0.88,1.22)$ & $1.44(1.05,1.98)$ \\
\hline & Widowed & $3.29(2.13,5.10)$ & $1.71(0.74,3.95)$ & $1.13(0.98,1.31)$ & $1.45(1.07,1.97)$ \\
\hline
\end{tabular}

Table 3. The cumulative cold and hot effects on mortality risk due to non-accidental, cardiovascular, and respiratory mortality. MMP: minimum mortality percentile; The MMP for RR of non-accidental, cardiovascular and respiratory mortality were 83,83 and 79 percentiles, respectively. The 5 th and 95 th percentiles temperatures were $3.0^{\circ} \mathrm{C}$ and $30.4^{\circ} \mathrm{C}$. $* \mathrm{P}<0.05$ (comparison between two periods).

In this study, we explored the modifications of marital status on the temperature-health relationship using YLL as an indicator. We found widowed individuals had a higher risk of mortality than did married people. However, when using YLL as an indicator, the results showed a different pattern, with a higher YLL identified in married persons.

Consistent with previous studies ${ }^{29,30}$, our study also found that elderly individuals were at higher risk of mortality than were younger individuals in association with both cold and hot temperatures. When using YLL as an indicator, elderly individuals also tended to have higher YLL than did younger individuals. Recently, researchers in Chongqing, Guangzhou and Zhuhai in China have also shown that the associations of high and low temperatures on YLL were higher in people aged $\geq 65$ years than those aged $<65$ years ${ }^{21,22}$. This finding was plausible from a biological perspective. Because thermal regulation systems may weaken with age, sensory perceptions may diminish and thermal homeostasis may decline ${ }^{31}$. In addition, elderly individuals frequently have pre-existing chronic diseases, which may make them more vulnerable to the adverse influence of temperature.

Gender also served as a modifying factor in the temperature-health association. A significant higher number of YLL and increased mortality risk due to respiratory disease were found in males. The difference may due to the socioeconomic and biological differences between the two genders.

Compared with mortality risk, using YLL as an indicator takes the age at which death occurs into account and, therefore, is useful for estimating premature death, which indicates the preventable years of life lost. Based on Table 1, we can see that although the number of married individuals was approximately 1.70 times the number of widowed individuals, the YLL of the former was 3.21 times that of the latter, which means the former had more preventable years of life lost. Taking the occurrence of death at different ages into consideration may result in more efficient resource allocation. The results of our study indicated that although widowed individuals were susceptible to extreme temperatures possibly due to the psychological vulnerability associated with spouse loss and living alone ${ }^{32}$, married people should not be ignored when implementing efforts to combat the harmful influence of extreme temperatures.

Our study has several strengths. First, we explored temporal variation in the associations of temperature on health before and after heat waves using the indicator of YLL. Second, the use of time-varying DLNM could assess exposure-response associations as continuous, non-linear shapes and account for the associations that cumulated over a lag period, thus generate a better understanding of the temperature-health associations and provide evidence for the future predictions. Third, researches analysing the modification of marital status on the temperature-YLL relationship were limited.

However, the data used in this study were only from one city in a subtropical region, and cautions should be taken when generalizing the results to other geographic areas. A large, multi-city study in a developing country might be higher impact in terms of adding to the literature on temperature and health. Second, temperature data were collected from a fixed monitoring site rather than indoors, but measurement errors may bias the results 
towards the null hypothesis. Third, the confounding effect of air pollutants was not controlled, but previous studies have reported that the associations of temperature were robust even after controlling for air pollutants ${ }^{33}$. Improvements need to be made in the future studies.

As a conclusion, our study provided insights into temporal variations in the temperature-YLL associations in a southern China city with typical subtropical climate. The heat associations increased after the extreme hot period, while the cold associations attenuated after this period. The temporal variation results indicated that there is a continued need for more efforts to be made to reduce heat-related YLL, even after periods of extreme heat have ended. In addition, the use of YLL as a mortality indicator provided a complementary method for detecting vulnerable subgroups, which may have important implications for the planning of public health interventions.

\section{Methods}

Data of mortality and YLL. The study was approved by the Institutional Review Board of Ningbo Municipal Center for Disease Control and Prevention (IRB 201603). Mortality data, including the underlying cause of death, were obtained from Ningbo Municipal Center for Disease Control and Prevention between January 2008 and December 2015, and a total of 263,789 registered non-accidental deaths were identified. Causes of death were classified using the International Classification of Diseases 10th version (ICD-10), and deaths due to non-accidental (A00-R99) and cardiovascular (I00-99) and respiratory (J00-99) diseases were analysed. The dataset comprised date of death, sex, age and marital status. Daily death count was defined as the number of deaths occurring on a single day. We calculated YLL by matching the patient's age to the life table for each death. The World Health Organization (WHO) standard life table for YLL was used (see Supplementary Table S2). Daily YLL were calculated by summing the YLL for all deaths on the same day. We stratified the sums by age ( $<75$ and $\geq 75$ years), gender (male and female) and marital status (the married and the widowed). Considering marital status, the number of married and widowed people accounted for $95 \%$ of the total number of deaths, thus we considered these two groups in the analysis.

Data of weather conditions. Daily meteorological data, including temperature and relative humidity, were obtained from the local meteorological bureau.

Data analysis. Generalized linear model (GLM) with a quasi-Poisson family was applied to derive the exposure-response curve for the association between temperature and mortality ${ }^{34}$. We included a variable for calendar days with a natural cubic spline function (7 degrees per year) to adjust for confounding related to seasonality and short-term fluctuations using day of the week as a factor. A natural cubic spline with 3 degrees of freedom was used for the daily relative humidity variable. To effectively measure for the effect of temperature, a distributed lag non-linear model (DLNM) was used ${ }^{35}$. This model can combine the conventional exposure-response association and the additional lag-response to describe complex non-linear and lagged dependencies, respectively. Specifically, we selected a cross-basis composed of a quadratic $\beta$-spline for the exposure-response function with three internal knots placed at equally spaced temperature percentiles $\left(25^{\text {th }}, 50^{\text {th }}\right.$ and $\left.75^{\text {th }}\right)$ and a natural cubic $\beta$-spline for the lag-response function with an intercept and three internal knots placed at equally spaced values on the log scale. Previous studies have shown that the lag effect of cold temperature persists for nearly two weeks, while the lag effect of hot temperature persists for less than one week; therefore, we chose a lag period of 21 days, which was sufficient to capture the effect of temperature. We tested these modelling approaches using sensitivity analyses. We validated the fit of the model by checking the residuals to ensure that autocorrelation had been successfully removed.

We determined the minimum mortality temperature (MMT) based on the exposure-response curves for cause-specific mortality. We estimated the relationship between daily YLL and temperature to facilitate a comparison between YLL and mortality. Because daily YLL had a normal distribution (see Supplementary Fig. S5), we used the Gaussian family. The independent variables that were used in the mortality model were also used in the YLL model. To ease interpretation, the curves were rescaled by centring them on the MMT derived based on cause-specific mortality and YLL.

In 2013, the frequency of extreme temperature days in the summer clearly exceeded that of other years (see Supplementary Table S3). To assess temporal variation in the temperature-YLL and temperature-mortality associations before and after that summer, we extended the first-stage models by adding a linear interaction between time and the cross-basis variables ${ }^{36}$. A parameterization index was derived by directly defining the main and interaction terms in the model. The former were the cross-basis variables described during the first stage of analysis, while the latter were interaction terms created by multiplying the main terms with a dummy variable $(0$ or 1) for time period. Regarding the lag effects of temperature, we selected Sep 30, 2013 as the cut point, which means that the time interval before the extreme hot period was considered to be Jan 2008 to Sep 2013 (period I) and the time interval after the extremely hot period was considered to be Oct 2013 to Dec 2015 (period II). Using time-varying DLNM, we predicted the exposure-lag-response association between the two periods. In addition, we stratified the analyses by age, gender and marital status. Considering age is strongly correlated with marital status, we stratified the marital status by age, and the findings on marital status were re-tested with adjustment for age. Significance tests of differences in the two periods were based on the coefficient of the interaction terms ${ }^{25}$.

Sensitivity analyses. Sensitivity analyses were performed on the parameters included in the models to test the robustness of our results. We extended the temperature lag to 27 days. We also plotted the extreme temperature exposure-lag-response curve to test whether the effect of temperature on health outcomes was effectively controlled. We also modified the degrees of freedom for time ( $6 \& 8 \mathrm{df})$. We removed relative humidity from these analyses to test the robustness of the results.

In our analysis, the $d l n m$ package in $\mathrm{R}$ software (version 3.1.2) was used to perform all analyses. $P<0.05$ (2 sided) were considered to be significant. 


\section{References}

1. The Eurowinter Group. Cold exposure and winter mortality from ischaemic heart disease, cerebrovascular disease, respiratory disease, and all causes in warm and cold regions of Europe. Lancet 349, 1341-1346 (1997).

2. Peng, R. D. et al. Toward a quantitative estimate of future heat wave mortality under global climate change. Environ Health Perspect 119, 701-706 (2011).

3. Basagaña, X. et al. Heat waves and cause-specific mortality at all ages. Epidemiology 22, 765-772 (2011).

4. Lin, Y. K., Wang, Y. C., Lin, P. L., Li, M. H. \& Ho, T. J. Relationships between cold-temperature indices and all causes and cardiopulmonary morbidity and mortality in a subtropical island. Sci Total Environ 461-462, 627-635 (2013).

5. Guo, Y., Barnett, A. G., Pan, X., Yu, W. \& Tong, S. The impact of temperature on mortality in Tianjin, China: a case-crossover design with a distributed lag nonlinear model. Environ Health Perspect 119, 1719-1725 (2011).

6. Ryti, N. R., Guo, Y. \& Jaakkola, J. J. Global association of cold spells and adverse health effects: a systematic review and meta-analysis. Environ Health Perspect 124, 12-22 (2016).

7. Amegah, A. K., Rezza, G. \& Jaakkola, J. J. Temperature-related morbidity and mortality in Sub-Saharan Africa: A systematic review of the empirical evidence. Environ Int 91, 133-149 (2016).

8. Yang, J. et al. Cardiovascular mortality risk attributable to ambient temperature in China. Heart 101, 1966-1972 (2015).

9. Ding, Z. et al. High diurnal temperature range and mortality: Effect modification by individual characteristics and mortality causes in a case-only analysis. Sci Total Environ 544, 627-634 (2016).

10. IPCC. Climate change 2013: the physical science basis. Working group I contribution to the fifth assessment report of the intergovernmental panel on climate change. Cambridge, UK and New York, USA: Cambridge University Press; 2013.

11. Wu, J. et al. Estimation and uncertainty analysis of impacts of future heat waves on mortality in the eastern United States. Environ Health Perspect 122, 10-16 (2014).

12. Linares, C. et al. The time trend temperature-mortality as a factor of uncertainty analysis of impacts of future heat waves. Environ Health Perspect 122, A118 (2014).

13. Bobb, J. F., Peng, R. D., Bell, M. L. \& Dominici, F. Heat-related mortality and adaptation to heat in the United States. Environ Health Perspect 122, 811-816 (2014).

14. Schifano, P. et al. Changes in the effects of heat on mortality among the elderly from 1998-2010: results from a multicenter time series study in Italy. Environ Health 11, 58 (2012).

15. Morabito, M. et al. Heat-related mortality in the Florentine area (Italy) before and after the exceptional 2003 heat wave in Europe: an improved public health response? Int J Biometeorol 56, 801-810 (2012).

16. Fouillet, A. et al. Has the impact of heat waves on mortality changed in France since the European heat wave of summer 2003 ? A study of the 2006 heat wave. Int J Epidemiol 37, 309-317 (2008).

17. Kyselý, J. \& Kríz, B. Decreased impacts of 2003 heat waves on mortality in the Czech Republic: an improved response? Int J Biometeorol 52, 733-745 (2008).

18. Huang, C. et al. The impact of temperature on years of life lost in Brisbane, Australia. Nat Clim Change 2, 265-270 (2012).

19. Yang, J. et al. The burden of ambient temperature on years of life lost in Guangzhou, China. Sci Rep 5, 12250 (2015).

20. Egondi, T., Kyobutungi, C. \& Rocklöv, J. Temperature variation and heat wave and cold spell impacts on years of life lost among the urban poor population of Nairobi, Kenya. Int J Environ Res Public Health 12, 2735-2748 (2015).

21. Li, J. et al. Influence of daily ambient temperature on mortality and years of life lost in Chongqing. Zhonghua Liu Xing Bing Xue Za Zhi 37, 375-380 (2016).

22. Li, Z. et al. Impact of air temperature on years of life lost among residents in Guangzhou and Zhuhai: a time-series study. Zhonghua Liu Xing Bing Xue Za Zhi 36, 720-724 (2015).

23. Lopez, A. D. et al. Global burden of disease and risk factors. New York: Oxford University Press; 2006.

24. Wang, H. et al. Age-specific and sex-specific mortality in 187 countries, 1970-2010: a systematic analysis for the Global Burden of Disease Study 2010. Lancet 380, 2071-2094 (2012).

25. Gasparrini, A. et al. Mortality risk attributable to high and low ambient temperature: a multicountry observational study. Lancet 386, 369-375 (2015).

26. Analitis, A. et al. Effects of cold weather on mortality: results from 15 European cities within the PHEWE project. Am J Epidemiol 168, 1397-1408 (2008).

27. Åström, D. O., Forsberg, B., Edvinsson, S. \& Rocklöv, J. Acute fatal effects of short-lasting extreme temperatures in Stockholm, Sweden: evidence across a century of change. Epidemiology 24, 820-829 (2013).

28. Petkova, E. P., Gasparrini, A. \& Kinney, P. L. Heat and mortality in New York City since the beginning of the 20th century. Epidemiology 25, 554-560 (2014).

29. Tian, Z., Li, S., Zhang, J., Jaakkola, J. J. \& Guo, Y. Ambient temperature and coronary heart disease mortality in Beijing, China: a time series study. Environ Health 11, 56 (2012).

30. Guo, Y., Punnasiri, K. \& Tong, S. Effects of temperature on mortality in Chiang Mai city, Thailand: a time series study. Environ Health 11, $36(2012)$.

31. Yu, W. et al. Daily average temperature and mortality among the elderly: a meta-analysis and systematic review of epidemiological evidence. Int J Biometeorol 56, 569-581 (2012).

32. Fouillet, A. et al. Excess mortality related to the August 2003 heat wave in France. Int Arch Occup Environ Health 80, 16-24 (2006).

33. Anderson, B. G. \& Bell, M. L. Weather-related mortality: how heat, cold, and heat waves affect mortality in the United States. Epidemiology 20, 205-213 (2009).

34. Bhaskaran, K., Gasparrini, A., Hajat, S., Smeeth, L. \& Armstrong, B. Time series regression studies in environmental epidemiology. Int J Epidemiol 42, 1187-1195 (2013).

35. Gasparrini, A., Armstrong, B. \& Kenward, M. G. Distributed lag non-linear models. Stat Med 29, 2224-2234 (2010).

36. Gasparrini, A. et al. Temporal variation in heat-mortality associations: a multicountry study. Environ Health Perspect 123, 1200-1207 (2015).

\section{Acknowledgements}

This study was supported by the National Natural Science Foundation of China (No. 81372950 and No. 81502780), the National Key Research and Development Program of China (No. 2016YFC0207103), Young Scientists Lift Plan from the China Association for Science and Technology (No. 2016QNRC001), the Medical Technology Program Foundation of Zhejiang, China (2014KYA202) and Science and Technology Program of Ningbo, China (2014C50027). The sponsors have no role in the study design, the collection, analysis and interpretation of data, the writing of the report, or the decision to submit the paper for publication. We thank the Ningbo Municipal Center for Disease Prevention and Control for providing the health data. Moreover, we thank the Ningbo Meteorological Bureau for providing the meteorology data. We also thank Dr. A. Gasparrini from the London School of Hygiene and Tropical Medicine, London, U.K. for providing R codes suggestions for our statistical analysis. 


\section{Author Contributions}

G.L. and J.H. designed the study and developed the analysis plan. These two authors contributed equally to the study. G.L. performed statistical analyses and took responsibility for the accuracy of the data analysis. J.H. wrote the manuscript. G.X. and X.Q. collected the data. X.P. gave advice for the statistical analysis. J.X. and T.Z. took responsibility for the integrity of the data. Y.Z. conducted the literature review and Q.L. helped prepare and method section. X.G. and T.H. directed its implementation, reviewed and edited the manuscript. All authors contributed to the revision and approved the final manuscript.

\section{Additional Information}

Supplementary information accompanies this paper at doi:10.1038/s41598-017-04945-6

Competing Interests: The authors declare that they have no competing interests.

Publisher's note: Springer Nature remains neutral with regard to jurisdictional claims in published maps and institutional affiliations.

(c) (i) Open Access This article is licensed under a Creative Commons Attribution 4.0 International

License, which permits use, sharing, adaptation, distribution and reproduction in any medium or format, as long as you give appropriate credit to the original author(s) and the source, provide a link to the Creative Commons license, and indicate if changes were made. The images or other third party material in this article are included in the article's Creative Commons license, unless indicated otherwise in a credit line to the material. If material is not included in the article's Creative Commons license and your intended use is not permitted by statutory regulation or exceeds the permitted use, you will need to obtain permission directly from the copyright holder. To view a copy of this license, visit http://creativecommons.org/licenses/by/4.0/.

(c) The Author(s) 2017 